\title{
COMO SABEMOS O QUE É VERDADE? O CASO DO MANA EM FIJI
}

Christina Toren

Começo por uma conversa que tive, por volta de 1982, com alguns jovens fijianos, enquanto caminhávamos pela estrada que liga as aldeias do litoral da ilha de Gau, na qual fiz trabalho de campo. Passávamos por um lugar onde, conforme alguém do grupo comentou, havia "alguma coisa" (e dua na ka). "O quê?" — perguntei. "Tevoro" [demônios] — foi a resposta, sotto voce. Eu não disse nada, mas meu ceticismo deve ter ficado estampado em meu rosto, pois eles começaram a asseverar que a terra por onde passávamos pertencia a um $v u$ (ancestral) conhecido por aparecer aos desavisados que andassem sozinhos naquela parte da estrada. Falei que já andara sozinha muitas vezes e nunca tinha visto um vu, e que estava realmente interessada nesta visão - por que não apareciam para mim? Todos riram: a idéia era ridícula. Mas por que não apareciam? Por quê? Mais risadas, e um dos rapazes disse, em tom que sugeria um desprezo divertido por minha falta de compreensão: "Era na sega ni basika mai vei kemuni" (Eles não vão aparecer aqui para você). "Mas por que não?" — insisti. "Baleta ni ko sega ni rerevaka!" (Porque você não tem medo deles!).

Esse pedaço de conversa é suficiente para transmitir uma idéia ainda prevalecente entre meus informantes fijianos: a de que o fato de os ancestrais ("demônios" é o termo usado para os ancestrais em seu aspecto maléfico) habitarem os lugares que são seus é por si mesmo evidente. A conversa também deixa claro que evidentemente não é assim no que me diz respeito. Esse choque de idéias é o quinhão reservado a todos os antropólogos em campo, e podem se passar muitos e muitos anos antes que sejamos capazes (se é que algum dia o seremos) de verdadeiramente dar crédito àquilo que nossos informantes nos dizem ser fato. Desse modo, podemos acabar caracterizando como crença aquilo que nossos informantes sabem e, ao fazê-lo, os representarmos impropriamente. Para que eu represente corretamente meus informantes fijianos, por exemplo, tenho de dizer que eles sabem que os ancestrais habitam os lugares que lhes pertencem. ${ }^{1}$ 
Isso me leva a observar que, se tivéssemos de afirmar, da forma mais concisa possível, qual teria sido a contribuição da antropologia para as ciências humanas, minha resposta seria a de que o corpus formado pela etnografia de diferentes povos, em diferentes momentos e lugares mostra, em primeiro lugar, que as pessoas em toda parte tomam como evidentemente verdadeiras suas idéias sobre si mesmas e sobre o mundo que as rodeia e, em segundo lugar, que o maravilhoso é justamente o mundo habitado confirmar em toda parte todos os variados entendimentos que formamos a seu respeito. O que as pessoas tomam como fato evidente não é em geral passível de confirmação segundo um modelo grosso modo científico, de acordo com o qual afirma-se uma hipótese para então tentar refutá-la. De modo geral, as pessoas raciocinam indutivamente e fazem racionalizações a posteriori. Assim, por exemplo, eu queria submeter a aparição de um ancestral a algo equivalente a um escrutínio empírico, e meus informantes divertiram-se precisamente porque sabiam que o que eu queria era irrelevante para os desejos do próprio ancestral.

Observei acima que esse choque de entendimentos é um lugar-comum antropológico; o que com menos freqüência se admite é que a profunda incomensurabilidade - com que às vezes nos deparamos - entre nossas próprias idéias e as daqueles cujas vidas analisamos pode nos impedir de reconhecer que não raro encontramos-nos em situação similar à daqueles que nos estão mais próximos: esposos, filhos, irmãos, amigos etc. Só o percebemos quando há desacordo entre nós, embora isso também fique bastante claro nas discordâncias que emergem, digamos, entre explicações rivais sobre o que realmente ocorre na economia. Para nós, na qualidade de antropólogos, o problema se apresenta como um caso particularmente poderoso daquele que enfrentamos em nossas vidas diárias: se realmente dermos crédito ao entendimento que outras pessoas têm do mundo, precisaremos reconhecer não apenas que o mundo que nos rodeia dá margem a todos os significados que os humanos podem criar, mas também que nossos próprios entendimentos não são menos passíveis de análise histórica — isto é, não menos explicáveis por meio da análise social — do que os das pessoas próximas. Segue-se daí a necessidade de fazer com que o poder explicativo de nossas etnografias resida em tornar analíticas as categorias de nossos informantes. ${ }^{2}$ É o que tentarei aqui.

O foco deste artigo é um longo extrato de uma conversa que tive em 2005 com um casal fijiano de meia-idade - Mikaele e sua esposa Makereta (para preservar sua privacidade, omiti os nomes reais).$^{3}$ Nossa conversa tratou da questão de como sabemos o que é verdade, e baseou-se em nossas várias idéias sobre o que as pessoas são — idéias que diferem em sua similaridade. 
Cada um de nós sustenta que a pessoa é um locus de relações — eu, porque sou uma antropóloga, para quem a intersubjetividade é a condição primária do ser humano, e Mikaele e Makereta porque, como aldeões fijianos, vivem suas vidas em torno da idéia de que a socialidade humana manifesta-se na obrigação mútua, veiqaravi, ou atenção/cuidados recíprocos (literalmente, "encarar-se, defrontar-se"). E cada um de nós, Mikaele, Makereta e eu, tem idéias bem estabelecidas (senão fixas) sobre o que é verdade e sobre como sabemos o que é verdade.

A palavra fijiana para denotar se algo é verdadeiro ou real é dina; ela também denota o que é apropriado ou genuíno, o que é honesto ou sincero. Vakadinata é uma forma transitiva do termo base, que significa "acreditar" ou "dar crédito a algo", "considerar uma coisa como verdadeira"; ivakadinadina pode ser traduzido como "prova" ou "evidência", também "confirmação" e "testemunho"4. No hinário metodista fijiano, todavia, o Credo dos Apóstolos é Na Vakabauta - que se pode traduzir aproximadamente por "a crença/ confirmação". Assim, a prece "crê em/ confirma Deus-Pai que está no céu" (vakabauta na Kalou, na Tamada vakalomalagi), "crê em/ confirma Jesus, seu filho" (vakabauta na Luve ni Kalou) e "crê em/ confirma a Bíblia" (vakabauta na Yalo Tabu) que "nos prova que somos os filhos de Deus" (vakadinadinataka mai ki na yaloda ni da sa luve ni Kalou). Com respeito ao Deus cristão e aos Deuses ancestrais*, a crença — no sentido de se considerar algo como verdadeiro, diante da possibilidade de que possa ser falso — não é uma questão para os aldeões fijianos com quem trabalhei. ${ }^{5}$ Eles sabem que Deus existe - isso não está aberto ao debate. O que importa é se uma pessoa pode ser vista atendendo $a^{*}$ um Deus.

\footnotetext{
* [N. T.]: No original, origin gods, referência à concepção de que os ancestrais, como deuses, dão origem a certas características da Terra.

* [N. T.]: O verbo inglês empregado no original é to attend, que tem ampla gama de significados: "estar presente, presenciar, assistir (a um evento, cerimônia etc.); estar junto de, acompanhar; assistir (alguém), dar assistência ou atenção, cuidar; servir". Por isso, a tradução do termo, amplamente empregado ao longo do artigo, flutua um pouco, dependendo dos contextos, ênfases, e das conotações próprias ao português, mas devendo-se atentar para algumas acepções (embora nem todas usuais) do verbo atender; "prestar atenção, prestar auxílio, seguir, acatar; dar atenção prestando serviço, escutar atentamente"; daí uma opção básica (mas não exclusiva) pela tradução quase literal; a polissemia ou polivalência nos vários contextos de aplicação são bem compatíveis com os do termo inglês e com a relação deste com o termo nativo - respeitando assim o espírito do artigo. Considerações similares valem para o substantivo attendance, traduzido por atenção no sentido de "disposição a ouvir alguém, ou ocupar-se com cuidado, zelo, dedicação".
} 
As categorias fijianas de crença e verdade mostram por que, de uma perspectiva antropológica, o significado de uma categoria não pode ser pressuposto; mostram por que é sempre necessária uma investigação etnográfica que determine de que modo a categoria é usada e quais suas possíveis implicações. E isso vale, por conseqüência, para o caso da categoria verdade, tal como usada por nós e pelos outros. É preciso, no mínimo, reconhecer que a investigação etnográfica deve (ao menos em princípio) implicar a nós mesmos tanto quanto a outros, em primeiro lugar porque a produção de significado é um processo histórico e, em segundo lugar, porque o mundo sustenta todos os significados que produzimos.

Diferentes idéias de conhecimento e crença estão associadas a diferentes idéias sobre verdade, e isso é certamente importante, pois constitui caso particular de um problema mais amplo: estamos, todos nós e em todas as partes do mundo, certos de que, de modo geral, o mundo se conforma à compreensão que temos dele. Meu interesse nesse fenômeno é instigado por uma experiência comum aos antropólogos: a de me dar conta, em intensidade crescente com o passar dos anos, de que minhas próprias idéias sobre o mundo e sobre o que é ser humano não são mais sólidas, mais defensáveis ou bem-fundadas - não são mais válidas - do que as de outras pessoas. Essa percepção resulta do trabalho de campo e de vinte anos de análise etnográfica das idéias e práticas fijianas, no decorrer dos quais tive constantemente de rever minhas perspectivas teóricas. Tal percepção é algo que nos é praticamente impossível de sustentar permanentemente como real, precisamente porque, não importa quão conscientes estejamos de que o conhecimento é transformado no mesmo processo em que é conservado (isto é, o processo de produção de significado ao longo do tempo), jamais podemos abrir mão de nossas certezas correntes sobre o mundo habitado - especialmente, talvez, se nos consideramos engajados, como me considero, em um esforço científico para compreender de que modo nós, humanos, nos tornamos aquilo que somos.

Minha preocupação geral como antropóloga é explicar algo do processo da autopoiese (autoformação, autoorganização), que se dá de modo biologicamente micro-histórico e se revela singularmente em cada um de nós. Minha explicação baseia-se na idéia da intersubjetividade como condição fundamental do ser humano. A intersubjetividade implica produzirmos significados a partir de significados que outros produziram e estão produzindo: isto é, como qualquer outro ser humano, estou emaranhada em relações multifacetadas com outros que têm seus próprios entendimentos das relações sociais e da constituição do mundo. Em qualquer encontro com outra pessoa, quem quer que seja, eu assimilo seu entendimento ao meu 
próprio e, ao fazê-lo, me acomodo - mais ou menos — às idéias que ela tem sobre o mundo e sobre nosso relacionamento. Cada um de nós nasceu em um mundo inacabado, em formação, que já foi tornado significativo em todos os seus aspectos materiais e, ao longo do tempo, produzimos esses significados novamente. Mostrei em outra ocasião porque daí se segue necessariamente que o significado é sempre emergente, nunca exatamente fixo; mostrei também de que modo, no processo ontogenético de produção de significado ao longo do tempo, o conhecimento é transformado na medida mesmo em que é conservado (ver Toren 1999a:1-21 e 2002). Esse processo micro-histórico de epistemologia genética torna as idéias de cada pessoa únicas, ainda que, do nascimento em diante, cada um de nós, querendo ou não, co-opte os outros na tentativa de fazer com que o mundo lhe faça sentido. ${ }^{6}$ E o processo é inevitavelmente percebido e vivido precisamente porque "fazer sentido" tem sempre tudo a ver com os outros - como fica claro em qualquer investigação etnográfica das idéias das crianças sobre o mundo habitado e sobre como elas chegaram a essas idéias.

Que fique claro que não estou meramente afirmando a idéia simplista de que "é tudo relativo"; tampouco pretendo sugerir que uma explicação científica não é diferente de qualquer outra descrição do mundo. O que estou indicando aqui é que o mundo habitado sustenta todas as nossas descrições historicamente constituídas a seu respeito, de tal modo que essas descrições, sempre e inevitavelmente parciais, se fazem objetivas de maneiras diversas. Assim, por exemplo, as idéias do povo Ambonwari sobre temporalidade, por mais que se distingam significativamente de nossas próprias idéias, permitem juízos temporais lineares derivados da comparação entre dois processos quaisquer, em termos de sua simultaneidade, duração e sucessão. O fato de que eles consideram pisinim (que significa "intervalo de tempo, duração limitada, período, estação") como intrínseco à pessoa e suas práticas não atenua essa linearidade. Eles não insistem, no entanto, em marcar uma distinção (como nós tentamos fazer) entre as perspectivas temporais linear e qualitativa. Ainda assim, nosso entendimento do tempo pode tornar-se explicável para eles, assim como o entendimento deles pode ser explicável para nós. ${ }^{7}$ Isso é possível, não porque certos conceitos de tempo são universais, mas porque todos nós temos de lidar com processos relativamente invariantes que se apresentam concretamente no mundo habitado - por exemplo, aqueles que tornam inevitável uma apreensão da temporalidade linear.

Pode ser difícil conceder que as idéias de outras pessoas sejam tão objetivamente corroboradas pelo mundo quanto as nossas, mas é somente assim que, na qualidade de antropólogo, se pode reconhecer a necessidade 
de uma teoria do ser humano que seja adequada para explicar por que as coisas se dão dessa maneira. Tal esforço de explicação pode ser, em última instância, impossível, pois lida com a historicidade da presença humana no mundo e implica, portanto, sua (do esforço) própria natureza histórica. Mesmo assim, parece-me importante buscar uma explicação antropológica válida. Essa minha conversa com Mikaele e Makereta constitui um caso para análise - cada um de nós se apega ao que sabemos ser uma verdade de fato demonstrável.

\section{O que vemos com nossos próprios olhos}

Mikaele recorre a um exemplo bem direto para iniciar sua demonstração de como sabemos o que é verdade: para determinar se Jone, seu filho adolescente, estava capinando o roçado, podemos recorrer ao testemunho de nossa visão. Aquilo que alguém fez, e não meramente o que dizem que foi feito, tem efeito no mundo - um efeito que se pode ver. Mikaele admite, todavia, que há coisas que sabemos sem realmente ver de modo direto, e cita Deus como exemplo.

\section{Texto 1}

Deus existe, mas nós não o vemos. Mas podemos dizer que isso é verdade [vakadinadinataka] porque nós [podemos] provar [vakadinadinataka] que existe um Deus [...] Eu digo que é verdade que existe um Deus. Há muitas coisas que posso mostrar a você — uma é o vento soprando. Perguntamos: de onde vem o vento? Outra, o Sol: quem criou o Sol? A Lua, quem criou a Lua? As estrelas, quem criou as estrelas? Essa árvore, quem a criou? Os animais, quem os criou? A grama [...] A chuva que cai [...] As árvores que crescem [...] Os muitos peixes no mar [...] [A]lgumas pessoas sabidas, hoje em dia, dizem que não existe Deus. Mas deixe que eles digam que não existe Deus; como as árvores crescem? Quem fez as árvores? Quem fez o Sol? Quem fez as marés? Quem fez a baixa da maré? [...] Quem fez os muitos peixes? [...] Nós simplesmente sabemos que existe um Deus [Kalou] que criou todos e tudo que existe.

Não podemos ver o Deus cristão, mas podemos conhecê-lo por meio das maravilhas de sua criação que estão evidentes para nós em toda parte, e que por si próprias proclamam a verdade de Deus. Mikaele fez menção a Deus na discussão, o que me levou a perguntar-lhe sobre os Deuses ancestrais: 


\section{Texto 2}

Os Deuses ancestrais [kalou vu] ainda existem. ... [Eles] são Deuses apenas do mundo [kalou ga ni vuravura] [...] [Eles] são exatamente como as pessoas. São nossa fonte antiga daquele tempo, eles são como Deuses daquele tempo [...] eles são nossos ... avós de gerações atrás [...] No momento em que você estiver dando atenção a ele, ele vai aparecer... [...] Assim como quando você está servindo a Deus [na Kalou]. É porque você quer servir a Deus que Deus então vai lhe dar o que você quer. É a mesma coisa com os Deuses ancestrais, se você atende a eles [...] [eles] vão lhe dar o que você quer. Mas isso é só uma coisa mundana [...] Eles ainda são eficazes [mana] [...] se você atende a eles. Ainda eficazes [mana]. Sim, mas como eu disse antes, só deste mundo. Deus ... o grande Deus [kalou levu]... o verdadeiro Deus [Kalou dina] está em desacordo [veicalati] com eles [...] O grande Deus tem grande poder sobre eles [...] julga-os. Ele é muito, muito mais poderoso que todos eles [...] não há Deus no céu ou na Terra que seja igual a ele [...] Como está dito na Bíblia: o grande Deus é um Deus ciumento [...] Ele não quer que você atente para outro Deus neste mundo. [...] Ele quer que você adore apenas a ele. Se você está dando atenção a um Deus ancestral, significa que você está em desacordo [veicalati] com seu comando [de Deus]. Assim, é como eu digo a você, ou para nós dois, o poder dos Deuses ancestrais vem deste mundo.

Nossa conversa passou então à seguinte indagação: se hoje em dia as pessoas estariam dando atenção aos Deuses ancestrais, e como Mikaele poderia sabê-lo? Os Deuses ancestrais, em contraste com o Deus cristão, são conhecidos pelo mal inevitável (embora um tanto defasado) que trazem para os que lhes servem; ou seja, pode-se saber se alguém serviu a um Deus ancestral (kalou vu) pelos males que se abatem sobre essa pessoa e sua família.

\section{Texto 3}

Como nós sabemos? Quando você vê como é que ele/ ela parece, os detalhes de sua vida e de sua casa [...] Quando você tenta saber ... bem, então, você olha para a casa e os filhos dele/ dela: os que estão na escola não vão ter bons resultados. Eles terão grandes dificuldades, os filhos terão grandes dificuldades. E tudo na sua vida familiar vai dar errado [...] Alguns, quando são acusados de atender a demônios, Deuses ancestrais, alguns, como eu já disse, fica evidente em seus filhos... seus filhos não vão se casar; se eles se casarem, não terão filhos. Se tiverem filhos, terão apenas um [...] Alguns desses que adoram um Deus ancestral, quando lhe dão atenção ... depois eles ficam sabendo que ele é maléfico - é o que eu escuto - eles depois retornam [para o bom caminho], eles pedem desculpas [vakasuka]. 
Logo, tais pessoas também podem ser reconhecidas por seus relatos de confissão. ${ }^{8}$ Não perguntei a Mikaele se era possível, em sua visão, refutar uma acusação específica de se ter atendido a um kalou vu, mas penso que ele começaria dizendo que sim, e que depois abandonaria essa posição, considerando que feiticeiros podem disfarçar-se de pessoas devotas e de bom coração, e que infortúnios podem abater-se sobre todos nós.

Na visão fijiana, infortúnios que se abatem sobre uma pessoa são muito provavelmente causados por malefícios de pessoas que estejam praticando feitiçaria (vakadraunikau, literalmente, "o caminho das folhas") — o que já seria por si só uma forma de atender a demônios (qaravi tevoro) ou aos Deuses ancestrais (qaravi kalou vu). Infortúnios que se abatem sobre outros, todavia, também podem muito bem ser o resultado de uma atenção egoísta a um Deus ancestral, e essa é a perspectiva de Mikaele em nossa conversa - ele não pensa na possibilidade de ser ele próprio afligido por infortúnios. Na moldura psicológica ocidental, esse tipo de raciocínio corresponde ao que se denomina "teoria da atribuição": quem vê um homem tropeçar diz que ele é desastrado, ao passo que o próprio homem que tropeça culpa a pedra que estava no caminho. Mas isso não nos diz muito: tão somente que as pessoas tendem a culpar forças, eventos externos ou os outros por aquilo que um observador tenderá a considerar como (de uma maneira ou de outra) culpa da própria pessoa. O que é mais interessante nesse caso fijiano é observar como a prática de atender a um Deus ancestral (qaravi kalou vu ou qaravi tevoro) constitui uma instância perversa de veiqaravi, atenção ou assistência dada e recebida em reciprocidade.

\section{Atenção mútua}

Em sua interpretação adulta mais estreita, na veiqaravi vakavanua (atenção/ cuidados de uns para com os outros, segundo os costumes da terra) é algo reservado para cerimônias como a do sevusevu ou a do reguregu - tratase, no caso da primeira, de apresentar yaqona aos chefes para pedir que reconheçam a presença da pessoa em um lugar ou, no caso da segunda, de apresentar um dente de baleia [cachalote] como reconhecimento de uma morte. O termo na veiqaravi vakavanua é sinônimo - pelo menos no que diz respeito a meus informantes adultos - de na cakacaka vakavanua (literalmente, "trabalhar, atuar, agir segundo os costumes da terra"), expressão que pode igualmente ser usada quando se fala, em geral, da prática de trabalhar conjuntamente em algum empreendimento coletivo. Veiqaravi designa também o ato de assistir aos chefes em sessões de consumo de 
yaqona, assim como designa o culto, quando a referência é o Deus cristão. Seu significado literal é "defrontar-se mutuamente", um arranjo espacial recorrentemente reiterado na disposição das casas na aldeia, nas posições ocupadas pelas pessoas em qualquer cerimônia, e na condução da vida cotidiana da aldeia. ${ }^{9}$

Veiqaravi tem a ver com as obrigações - que atravessam casas, clãs e yavusa ${ }^{10}$ - de se dar ou prestar assistência mútua nos rituais do ciclo de vida cotidiano, em celebrações como Natal e Ano Novo, e em atividades como a construção de casas, instalação de cabos elétricos na aldeia etc. Todas essas ocasiões requerem que as pessoas se reúnam para juntas beberem yaqona (Hocart 1952:51-52). Qualquer que seja o motivo explícito para se oferecer yaqona, tal bebida é sempre oferecida aos chefes e, implicitamente, aos Deuses ancestrais que "ficam logo atrás" de qualquer chefe instalado. Preparar, servir, aceitar e beber de uma vasilha de yaqona são atos realizados sempre "conforme o costume da terra", e não se deve deixar um grupo que está bebendo junto até que o grande recipiente central esteja seco (maca). Yaqona é a bebida dos chefes; eles recebem a raiz como tributo e a redistribuem como bebida, que tem de ser aceita: isso é válido tanto na presença quanto na ausência de algum chefe. ${ }^{11} \mathrm{O}$ espaço em que se bebe (no interior ou ao ar livre) é valorizado de tal modo que os chefes sentam-se acima (i cake) do grande recipiente central de yaqona, voltados para o lugar daqueles que se sentam abaixo ( i ra) da yaqona, que estão por sua vez voltados para os chefes acima deles. A mutualidade se revela e, ao mesmo tempo, é constituída, no uso cotidiano ritualizado do espaço e por meio dele - isto é, mutualidade e veiqaravi, tal como dadas no uso ritualizado do espaço, são mutuamente constitutivas ou, mais radicalmente, consistem em aspectos uma da outra. ${ }^{12}$

Os aspectos benigno e maligno dos Deuses ancestrais (kalou vu) se fazem eficazes (mana) por meio, respectivamente, da forma adequada e da forma perversa de veiqaravi. Em Fiji, aquele que inveja seus parentes e deseja prejudicá-los, ou que deseja egoisticamente riquezas ou poder, bebe yaqona sozinho - ou, provavelmente, na companhia do cônjuge — fazendo libações, invocando o nome de um Deus ancestral e proferindo o nome de um parente próximo como vítima-oferenda ao Deus. ${ }^{13}$

\section{Texto 4}

Alguns - a história que ouvimos sobre isso - alguns só atendem a eles dentro da casa. Alguns se conhecem, têm conhecimento disso como esposos — o homem sabe e também a mulher [...] Quando alguém diz: "ele/ ela está no caminho 
dos demônios", então outra pessoa também diz "mas ele/ ela não sabe sozinho/ sozinha" [...] Seu esposo/ sua esposa também sabe.

Minha compreensão, vinte anos atrás, foi a de que oferecer o nome de um parente seria algo invariavelmente bem-sucedido - isto é, o Deus ancestral, dotado de poder pelo serviço a ele prestado, se abatia sobre a pessoa nomeada em uma morte de outro modo não explicável. Mas, de acordo com o que Mikaele me contou, muitas mortes e outros infortúnios são atribuíveis à circunstância de o Deus ancestral voltar-se contra seu próprio servidor. Qualquer que seja o caso, pode-se reconhecer alguém que se volta para um Deus ancestral pela maneira como bebe yaqona.

\section{Texto 5}

[...] o modo como ele/ ela bebe yaqona ... não é como o das pessoas [comuns], continua bebendo yaqona todos os dias, bebendo yaqona, bebendo yaqona. Junto com ... junto com seu esposo/ sua esposa, eles estão bebendo yaqona, os dois dentro da casa deles. [Em contraste,] se bebemos yaqona, estamos contando histórias uns para os outros, muitos de nós [juntos].

A ênfase de Mikaele na responsabilidade conjunta dos cônjuges mostra como, ainda que a casa seja o fundamento [yavu] de toda a vida social, o veiqaravi envolve relações entre várias casas. Um casal que, de modo egoísta, deseje aumentar o sucesso de sua própria casa por meio de ofertas a um Deus ancestral está fadado a prejudicar outras casas e, em última instância, a sua própria. Servindo ao Deus em sessões de ingestão de yaqona a portas fechadas, o casal se põe em desacordo (veicalati), não apenas com o Deus cristão mas, implicitamente, com os chefes e com os Deuses ancestrais em seu aspecto benigno - ficando atrás dos chefes instalados. O consumo de yaqona é central em todas as cerimônias fijianas e, enquanto tal, está sob a égide dos chefes, dos Deuses ancestrais e do Deus cristão. O reconhecimento dos Deuses ancestrais é por vezes explicitado em discursos cerimoniais, porém, quanto ao restante, está sempre implícito nos títulos honoríficos dos chefes, empregados em tais discursos e referindo-se a yavu tabu - as fundações proibidas da casa - cujos donos (e únicos ocupantes) são os ancestrais fundadores. O Deus cristão é invocado na prece que acompanha os discursos cerimoniais. O fato de um casal atender de modo exclusivo a um Deus ancestral dá a entender que sua casa pode produzir sozinha a própria prosperidade, sem o apoio de outras, dos chefes ou do Deus cristão - em suma, sem referência ao veiqaravi. Mas o infortúnio futuro é inerente a essa recusa. 


\section{Por que servir a um Deus ancestral traz o infortúnio}

Nas regiões central e oriental de Fiji, entre os grupos de etnia fijiana, as relações sociais em geral, e a chefia em particular, se dão em função de conceitos opostos e complementares sobre igualdade competitiva (como, por exemplo, na reciprocidade equilibrada das trocas entre casas e clãs ao longo do tempo) e hierarquia (como, por exemplo, nos tributos aos chefes). De fato, pode-se argumentar que aqui a hierarquia instituída e a igualdade competitiva fundem-se como aspectos de uma só idéia de dualidade antitética, segundo a qual cada tipo de relação social depende do outro para sua própria continuidade (ver Toren 1999a:163-181). Essa oposição radical permeia a vida diária em Fiji e conforma, por exemplo, as relações sociais, o parentesco, a chefia e as noções de pessoa. Na aldeia, a oposição na qual se fundem hierarquia e igualdade competitiva expressa-se na posição da pessoa em relação a outros, no tempo e no espaço.

O status de uma pessoa na comunidade mais ampla — derivado de uma interação entre posição hierárquica (chefe ou plebeu), posição geracional (mais velho ou mais novo) e gênero (esposa ou irmã em relação a determinado homem) - demarca seu lugar acima (i cake) ou abaixo (i ra) de outros em qualquer reunião em uma casa, em um recinto de reuniões da aldeia ou na igreja. Esse eixo acima/ abaixo pode ser aplicado tanto a um plano horizontal único (por exemplo, uma das extremidades no chão da igreja, do local de reuniões da aldeia, ou de uma casa qualquer é acima, e a outra é abaixo) quanto a um plano vertical (por exemplo, ao passar por outras pessoas, é educado adotar a postura curvada e respeitosa chamada lolou). Em Gau, todos os encontros, reuniões, banquetes, cultos etc. têm lugar nos espaços ritualizados da casa, da igreja, ou do grande recinto de reuniões da aldeia, e todos os moradores a partir de aproximadamente cinco anos de idade sabem qual área é acima e qual é abaixo, naquele espaço determinado. O status relativo das pessoas fica evidente na disposição espacial que adotam ao longo desse eixo.

O eixo acima/ abaixo constitui-se a partir de uma transformação, no ritual, do veiqaravi (literalmente, "defrontar-se mutuamente", e também "atenção/ cuidados recíprocos"), que descreve a disposição das casas no espaço da aldeia e sugere mútuas obrigações rituais transclânicas. Além disso, qualquer casa é, via de regra, orientada de maneira que a "porta da terra" fique diante da "porta do mar" da casa ao lado, evocando assim as relações entre a gente da terra e a gente do mar. Veiqaravi pode referir-se, aqui, à reciprocidade equilibrada que vigora ao longo do tempo nas trocas entre casas, clãs e yavusa; o termo, entretanto, também designa a "atenção aos chefes", quando referido a uma cerimônia de chefia, ou o "culto", quando 
referido a um serviço religioso na igreja. Assim, o próprio termo veiqaravi contém a tensão entre igualdade competitiva e hierarquia instituída que possibilita, no ritual da yaqona, a transformação das trocas recíprocas entre casas em tributo aos chefes (ver Toren 1990:74-89 e 1999a:67-82). A antítese em que se fundem hierarquia e igualdade competitiva remete aqui àquela entre parentes não-casáveis (tendo como referência paradigmática a casa e o clã hierárquicos) e parentes casáveis (que, como primos cruzados, são iguais, cruzando casas e clãs). ${ }^{14}$

O casal traz para si mesmo infortúnios porque recusa o princípio de socialidade segundo o qual é veiqaravi que conforma a atitude ou maneira própria do parentesco, da chefia, da terra, da igreja. Considerado como princípio de socialidade, veiqaravi permite todas as possibilidades, todas as sutilezas de relacionamento que se revelam no comportamento das pessoas quando estão juntas, em presença das demais. Contudo, quando alguém serve a um Deus ancestral, isso é tudo que a pessoa pode ser: seu servo. Os fijianos sustentam explicitamente que o poder de um chefe, dos Deuses ancestrais e do Deus cristão reside na atenção que as pessoas lhes dão, na disposição delas para escutá-los (vakarogoca) e fazer conforme dizem - isso torna a palavra deles eficaz (mana) e, portanto, verdadeira (dina). Uma vez a pessoa tendo começado a atender ao Deus, e uma vez que o mana deste depende da pessoa, seu desejo pela atenção é insaciável; mesmo abjurando todas as demais obrigações, não é possível para a pessoa cumprir as promessas que fez ao Deus. Como diz Mikaele:

\section{Texto 6}

[...] simplesmente chega ao fim, ao ponto máximo, simplesmente chega ao desfecho ... Virá o momento em que o Deus ancestral se tornará seu inimigo, e então morderá você outra vez. Desse jeito. Não é possível servir para sempre, deixar a bebida continuar a correr, só continuar, continuar, continuar. O momento virá em que vocês dois serão inimigos outra vez [...] O Deus ancestral é outra vez seu inimigo [...] Como eu disse antes: aquele momento de seu contrato, seu contrato com ele vale o tempo inteiro [é aceito como um sacrifício]. Ele continua valendo, valendo. Do momento em que você passa a não cumprir seu contrato, a partir daquele momento ele irá morder você de novo por causa disso.

O que tento demonstrar aqui é que, da perspectiva de Mikaele, aquilo que ele tem a dizer é uma verdade evidente por si, já que é um resultado inevitável de uma lógica inexorável que está dada no veiqaravi e que ele vive dia após dia, momento após momento. 


\section{Mas como você pode saber?}

Em momento anterior de nossa conversa, eu havia pressionado Mikaele para que me contasse sua opinião a respeito de um caso particular.

\section{Texto 7}

Chris: Mas você acredita na história sobre esses dois?

Mika: Existem muitas histórias como essa que eu escuto, mas não posso provar porque não vemos nada [...] Talvez alguém veja [...] e acuse os dois por isso, mas quanto a mim ... eu não posso provar porque não vi com meus próprios olhos nada do que eles [dois] fizeram. [Quanto a mim e a você], nós [dois] somos novos aqui, nós [dois] não vimos nada, nós [dois] não podemos dizer se é verdade ou mentira [...] Algumas, algumas explicações disso, aqueles que estão dando atenção a um Deus ancestral, a explicação disso que eu ouço sobre eles é que eles são boas pessoas, são pessoas que se importam com os outros. Para encobrir seu comportamento e não nos deixar saber que eles estão dando atenção a um Deus ancestral, eles geralmente se importam conosco.

Chris: Isso significa que é muito, muito difícil...

Mika: Difícil. A não ser que você o/a veja quando ele/ela está servindo [o Deus], que você realmente veja com seus olhos quando ele/ela está bebendo um pote de yaqona [enquanto] fala.

Chris: Você viu?

Mika: Não, estou só dizendo.

Chris: Ah.

Mika: Você pode então saber que é ele/ela. Eles dizem, os que falam disso, que as pessoas que nós vemos, aqueles que acusamos de dar atenção a um Deus ancestral, alguns deles têm esse tipo de comportamento - sempre se importando, sempre gentis, para esconder seu ... [Alguns] freqüentam a igreja. [...] Alguns dos que são acusados são guias leigos* para esconder seu comportamento.

$[\ldots]$

Chris: Isso quer dizer que não é possível...

Mika: ...saber.

Chris: É, não dá.

Mika: A não ser que você veja, que você o veja em algum lugar.

$[\ldots]$

Mika: Alguns, alguns dizem - eu mesmo ainda não vi — alguns deles dizem que eles fazem danças para a Lua. [...] Eles dançam assim [movendo as mãos

" [N. T.]: No metodismo, a figura correspondente ao pregador leigo de outras igrejas cristãs. 
COMO SABEMOS O QUE É VERDADE? O CASO DO MANA EM FIJI

em um rápido meke], assim. Alguns falaram disso. É o caráter deles. Sim, algumas pessoas conseguem pegá-los, pegam quem está dançando para a Lua [meke vula].

Chris: É verdade?

Mika: Sim. Algumas pessoas contam.

Chris: Na aldeia? Dentro da aldeia?

Mika: Na aldeia e nas outras aldeias de Fiji. Essa coisa, Christina, se dá em todas as aldeias, em todas as aldeias existem algumas pessoas que são acusadas de feitiçaria. Em todas as aldeias de Fiji.

Chris: É também assim aqui... aqui em Sawaieke?

Mika: Aqui também há alguns.

Chris: Sim, mas o que é difícil, para mim, é...

Mika: Sim.

Chris: ... como... você... sabe?

Mika: ... como... você... sabe?

Mikaele sabe o que vou dizer; ao longo dos anos ele me ouviu fazer diversas vezes essa pergunta. Ele a conhece e é capaz de repeti-la comigo. Ele também se diverte com meu insistente ceticismo, pois sabe que algumas pessoas se voltam para os Deuses ancestrais. Nossa conversa continua:

\section{Texto 8}

Chris: Sim, mas você acredita/ confirma [vakabauta], Mikaele, você me disse que há algumas dessas pessoas aqui, em Sawaieke. Como você sabe que há? Mika: É só a história que ouvimos. Só histórias assim, como essa, que nós ouvimos.

Quando levanto a questão da fofoca, Mikaele admite que isso é verdade, dizendo-me que é claro que "alguns desses que contam histórias querem fazer mal a [outros], eh? [em inglês:] Estragar? Estragar um ao outro?". E ele sem se abalar aceita, simultaneamente, tanto o fato de que pode ser mesmo impossível obter prova conclusiva de feitiçaria, quanto o que o antigo pastor metodista, já falecido, me dissera: que não acreditava nas histórias que lhe contavam - por exemplo, que o peixe que alguém lhe dera era o presente de um feiticeiro e provavelmente lhe faria mal.

\section{Texto 9}

Chris: [O reverendo Vosaki disse à sua esposa]: "Pegue o peixe, agradeça por ele, cozinhe-o. Ele vai estar saboroso". Ele não acreditava nesse tipo de história. Mika: Mmm. É uma crença fijiana [na vakabauta vakaViti]. 
Makereta: [acorda, intervém] Quanto a nós, fijianos, é impossível que desapareça. [...]

Mika: Ele não pode acusar a pessoa. Ele é um pastor. Ele vai aceitar tudo que lhe trazem. Ele não pode nem uma única vez acusar uma pessoa [e] e ele não pode dizer: "aquela coisa, aquela coisa, aquela coisa" [i.e., ele não pode aceitar alguns pratos, por exemplo, e rejeitar outros]. Não. Ele vai só pegar e dizer obrigado. [...] Esse é o jeito deles — todos os pastores da igreja, os guias leigos — esse é o comportamento deles, de todos eles. Aqui, não é possível discriminar entre pessoas, tudo o que é dado daqui ou dali, eles aceitam [...] A crença segundo a Bíblia, segundo a Igreja cristã, é: não acuse nenhum de seus parentes. Aceite tudo que seus parentes lhe dão.

Durante toda a nossa conversa, Mikaele, um metodista devoto (como sua esposa) recorreu a ensinamentos cristãos para sustentar o que afirmava, mas tais idéias são assimiladas à noção fijiana da pessoa como locus de relações: a maneira de alguém se distinguir é demonstrar quem ele é como função do que lhe é dado ser nas relações com outros. Na medida em que os pastores fazem o que lhes é dado fazer, não há como prejudicá-los. Além disso, os Deuses ancestrais em seu aspecto maléfico tornam-se manifestos em relação à pessoa cujo egoísmo se revela na atenção mesma a um Deus; pela mesma razão, os próprios Deuses ancestrais fornecem o potencial para a feitiçaria; na realidade eles a inventaram, pois, como diz Makereta, eles querem ter a atenção das pessoas. Apenas assim, podem mostrar-se mana, eficazes.

\section{Texto 10}

Makereta: ... essa coisa foi criada por nossos ancestrais. Eles só criaram isso para que pudessem ser cultuados como Deuses, Deuses ancestrais [...] Alguns de nós, cristãos, não queremos saber disso — que existem ainda algumas pessoas que crêem [ou se confirmam] em diferentes Deuses, Deuses ancestrais. [Mas] elas se prestam a eles, não importa se a igreja interfere, as pessoas só se prestam a eles porque simplesmente os seus Deuses são os nossos ancestrais.

\section{Mana como força material no mundo}

A efetividade dos Deuses ancestrais, assim como a dos chefes, reside nos atos voluntários de atenção por parte das pessoas. E como são as pessoas que tornam os Deuses e chefes poderosos, os fijianos têm amplos indícios que confirmam sua idéia de mana como eficácia, verdadeira porque inteira- 
mente material: o poder do Deus cristão se evidencia na atenção de muitos milhões de pessoas em todo o mundo, e é manifestamente maior que o poder dos Deuses ancestrais fijianos. Da mesma maneira, todos podem ver em que medida as palavras de um chefe são ou não mana; é algo evidente na disposição voluntária das pessoas em dar-lhe atenção e na prosperidade de seu país. ${ }^{15} \mathrm{~A}$ fórmula ritual que pontua falas cerimoniais, mana... e dina, é traduzida por "é eficaz, é verdadeiro", mas por sempre referir-se à fala que a precede, sua tradução mais oportuna seria "tem efeito, é verdadeiro"16. Considere-se o seguinte exemplo no qual, por ocasião das cerimônias de luto por um chefe falecido, um homem com status de chefe oferece um dente de baleia às pessoas cuja tarefa consiste em assistir ao chefe morto.

\section{Texto 11}

Eu toco, senhores, a corda do dente de baleia [tabua (dente de cachalote)], para que nossos chefes sejam saudáveis, que nosso país seja de paz e abundância [sautu], um país de amor mútuo [veilomani]. [Literalmente: que o sau - o comando ou proibição de um chefe - se estabeleça em nosso país, que este possa ser um lugar de cuidados mútuos]. A palavra já foi ouvida. É eficaz, é verdadeira [Mana. ... e dina].

Se um chefe não faz valerem suas palavras, o que ele diz não é verdadeiro. Um alto chefe no exercício da chefia é exemplo vivo do poder imanente dos ancestrais, poder que, hoje, em sua face legítima, está sob a égide do Deus cristão. O sau - comando ou proibição proferidos por um chefe instalado - prejudica de modo adequado e inevitável qualquer pessoa de seu povo que se recuse a ouvir o chefe; isso quer dizer que sua palavra mana, sua palavra tem efeito: em virtude de serem proferidas, as palavras do chefe trazem à existência a condição que proclamam. ${ }^{17}$ Mas se um chefe supremo falha em seus deveres para com o povo, se ele se apega a bens e objetos de valor que lhe são dados como tributo, e não mostra que os redistribui, então não mais se verá seu país prosperar; sua palavra, evidentemente, já não será mana, e as pessoas não terão nada a temer se decidirem suspender sua lealdade (nodra vakarorogo vua, literalmente, "o ato de escutá-lo"). ${ }^{18}$ Em outras palavras, os fijianos sabem que são eles que, graças à sua disposição em prestar atenção e tributos, conferem poder a seus chefes, os quais por sua vez fazem prosperar as pessoas e a terra. Essa idéia se estende tanto aos Deuses ancestrais quanto ao Deus cristão. O poder maléfico dos Deuses ancestrais pode ser liberado por meio da feitiçaria - o ato de atender a um ancestral, prestado por uma única pessoa, que age sozinha ou com seu cônjuge. Da mesma maneira, os Deuses ancestrais já não são, de modo geral, efetivos, 
porque "ninguém mais dá atenção a eles", enquanto o poder do Deus cristão é plenamente revelado em seus muitos milhões de fiéis. A verdadeira fonte da fortuna de uma pessoa, todavia, independentemente de quão boa ou má seja essa pessoa, sempre se fica por averiguar — ela terá sido efetivada pelo Deus cristão, pelos ancestrais atuando sob sua égide, ou pelos ancestrais em sua face maligna?

A verdade, portanto, não está necessariamente dada na natureza das coisas, e não pode estar sempre sujeita à verificação; ela é antes um efeito que se pode conhecer, podendo levar algum tempo para tornar-se evidente. ${ }^{19}$ A idéia fijiana é de que a fala ou, mais geralmente, a palavra (vosa) tal como falada ou escrita, pode ser mana, eficaz, e por isso o que é verdade (dina) pode ser um resultado, e não algo que já se encontra na natureza das coisas.

Aqui julgo interessante considerar a força moral da linguagem. Em artigo recente, recorri a meu trabalho de campo em Fiji para argumentar que há sempre uma força moral específica inerente a formas igualmente específicas de uso da linguagem. O artigo utilizava um caso público de significação coletiva para mostrar de que modo a verdade pode ser vista, não como um absoluto, mas como função daquela força moral específica que está, ela própria, incrustada em e constituída por relações sociais cotidianas que podemos analisar em termos de relações sexuais, parentesco, chefia e noções de pessoa. O leitor com certeza sabe que os fijianos possuem (é claro!), como qualquer pessoa, capacidade para testar hipóteses e distinguir entre uma asserção empiricamente fundamentada e outra que não o é. Em alguns casos, porém, especialmente aqueles que envolvem situações sociais complexas, o que é visto como verdade pode ainda assim ser entendido como resultado de uma luta entre diversos falantes — cada um com a firme intenção de estabelecer definitivamente sua própria verdade para as outras pessoas (ver Toren 2005). Assim, o que fascina os fijianos que conheço são as relações sociais, as obrigações inerentes ao veiqaravi - atenção/ cuidados mútuos — seu cumprimento ou evitação, e como elas manifestam e constituem ao mesmo tempo a atitude conforme o parentesco, a atitude dos chefes e a atitude fijiana.

Pois bem, supondo que eu esteja correta em dizer que há sempre uma força moral específica inerente a formas também específicas de uso da linguagem, como é que chegamos a percebê-la como tal? Os detalhes do material fijiano sugerem que são os aspectos ritualizados do uso da linguagem que estruturam o modo com que os falantes vão constituindo, no decorrer do tempo, suas idéias a respeito daquilo para que serve a linguagem e de qual poderia ser sua força moral. ${ }^{20} \mathrm{E}$ eu afirmaria que é assim em toda parte pois, para todos nós, os aspectos paralingüísticos do uso da linguagem 
são inevitavelmente, em algum grau, ritualizados — isto é, explicitamente tomados como regidos, em algum grau, por regras, e ao mesmo tempo fortemente impregnados de significados. Tudo isso me sugere a necessidade de estudar o processo ontogenético por meio do qual as crianças constituem suas idéias sobre a fala, sobre o que ela realiza, e as condições que a tornam boa e correta — isto é, suas idéias a respeito da força moral presente em aspectos ritualizados do uso da linguagem.

Em trabalhos anteriores, mostrei que a experiência infantil de incorporar um comportamento ou uma série de comportamentos rituais é crucial para o processo de desenvolvimento graças ao qual, ao fim de algum tempo, as crianças vêm a atribuir significado àquele comportamento, de tal modo que a performance deste torna-se simbólica do referido significado e, enquanto tal, obrigatória (Toren 1990, 1999a:83-124 e 2006.). Em outras palavras, o poder de comunicação do ritual não está dado no ritual mesmo, precisamente porque ele, em contraste com a fala, não pode declarar o próprio significado. Mais precisamente, o poder comunicativo do ritual é o resultado de um processo de aprendizado em que, com o tempo, a pessoa torna significativos certos comportamentos ritualizados. Segue-se daí que, como adulta, sou coagida pelos rituais e comportamentos ritualizados que tornei significativos, porque bem antes de me perguntar o que poderiam significar, eu já havia incorporado um conhecimento indelével do "que" e do "como" dessas práticas rituais específicas. Afirmo que o mesmo vale para boa parte da prática paralingüística, e que assim sendo, decorre daí que a compreensão de qualquer enunciação específica envolve a compreensão de sua força moral, sendo ambas aspectos de um mesmo processo - sendo esta uma observação que põe em questão quaisquer pressupostas distinções entre a força proposicional e a força ilocutória de um enunciado. Será talvez preferível considerá-las, não como tipos diferentes de significado, mas como aspectos uma da outra - ou seja, a força proposicional de uma expressão e seu impacto performativo são inextricáveis e estão ao mesmo tempo entranhados em uma idéia a respeito daquilo para que serve a linguagem (cf. Austin 1962 e Bloch 1974).

Aprendendo o emprego da linguagem, aprendemos sobre a linguagem mesma, o que ela faz e como; e aprendemos também a estar em relação com outros; a idéia que fazemos de nós mesmos enquanto sujeitos vai se constituindo como função da intersubjetividade - um processo de contínua diferenciação, em que estamos sempre nos tornando nós mesmos. Assim, um estudo sistemático de observação participante a respeito, por exemplo, de crianças francesas da alta classe média, na faixa, digamos, dos quatro aos doze anos, na escola, em casa e alhures, poderia revelar a ontogênese da idéia 
de que a linguagem deve ser valorizada como instrumento analítico, um meio de explanar a natureza do mundo e a condição humana. ${ }^{21}$ De fato, no curso desse mesmo estudo, poderíamos também descobrir a ontogênese da idéia oposta e complementar de que o próprio discurso é constitutivo daquilo que as pessoas são e do que podem ser. Por mais que pareçam antitéticas, essas idéias são, da mesma forma, aspectos uma da outra, cada uma apresentando independência apenas aparente, como os dois lados da superfície contínua em que consiste uma faixa de Moebius - e a compreensão da ontogênese dessa oposição nos permitiria tornar tais idéias genuinamente analíticas para aqueles cujas vidas elas podem de fato conformar. ${ }^{22}$

Através de minhas relações com meus informantes fijianos vim a perceber que é somente captando, ao longo do tempo, o sentido da prática paralingüística que chegamos a conhecer a força moral do que é dito ou escrito, que adquirimos nossa idéia de como sabemos o que é verdade. Segue-se que uma compreensão da força moral da linguagem acabará necessariamente por se constituir no mesmo processo pelo qual a pessoa se torna um falante nativo da sua língua e, assim, forma um entendimento das condições que tornam verdadeira uma afirmação. Essas idéias, por sua vez, envolvem, como vimos, noções particulares do ser humano e modos particulares de apresentá-las como aspectos do mundo que são objetivamente dados. Mana... e dina. É eficaz... é verdadeiro.

Recebido em $1^{\circ}$ de julho de 2006

Aprovado em 3 de julho de 2006

Traduzido por Amir Geiger e Marcela Coelho de Souza

Christina Toren é professora de antropologia na Universidade de Saint Andrews, Inglaterra. E-Mail: <christina.toren@st-andrews.ac.uk> 


\section{Notas}

${ }^{1}$ Compare-se Donald Davidson, para cujo trabalho João de Pina Cabral chamou minha atenção. Por exemplo: "Não pode estar correta uma teoria da interpretação que faça com que um homem aceite muitas sentenças falsas; é preciso que, de modo geral, uma sentença seja verdadeira quando o falante assim a considerar. Em certa medida, conta como ponto positivo para um método de interpretação o fato de ele só dar uma sentença por verdadeira quando os falantes sustentam que ela o é. Mas é claro que o falante pode estar errado, assim como o intérprete. Portanto, o que deve afinal contar a favor de um método de interpretação é ele fazer intérprete e falante concordarem de modo geral: segundo tal método, o falante considera que uma sentença seja verdadeira sob certas condições especificadas, as quais se verificam, na opinião do intérprete, exatamente nos casos em que o falante considera a sentença verdadeira" (Davidson 1984:169).

${ }^{2}$ Tentei formular essa idéia em Toren 2002. Não me dei conta, porém, de que em algum momento do processo de editoração e copidesque, as últimas palavras do penúltimo parágrafo, "tornadas analíticas" [rendered analytical], foram mudadas para "tornadas analisáveis" [rendered analysable], e assim meu artigo perdeu inteiramente seu argumento central.

${ }^{3} \mathrm{O}$ que se encontra aqui incluído são extratos editados de uma longa conversa que envolveu interrupções, murmúrios céticos, esclarecimentos e risadas de ambas as partes. Por exemplo, no início, talvez Mikaele estivesse preocupado, pensando que eu quisesse apanhá-lo em erro, mas depois que consegui deixar claro que não se tratava disso, ele passou a discutir com interesse os temas que cada um de nós ia levantando. Em alguns momentos, ele era loquaz, em outros, reticente, e em outros ainda incitei-o a dizer mais - talvez o processo de transcrever, editar e traduzir faça parecer por demais espontâneo o que aqui está relatado; mesmo assim, creio que me mantive fiel ao espírito da conversa.

${ }^{4}$ Devo a Georger Milner (comunicação pessoal), autor de Fijian Grammar, a meticulosidade dessas glosas para dina e seus derivados.

${ }^{5} \mathrm{O}$ trabalho de campo em Fiji somou 20 meses entre 1981 e 1983, quatro meses em 1990, dois meses em 1993 e dois meses em 2005. Em 2005, a aldeia principal de Sawaieke tinha uma população que oscilava em torno de 330 habitantes, aproximadamente, e o território Sawaieke (vanua ko Sawaieke — todas as oito aldeias), possuía cerca de 1800 habitantes. A economia é um misto de subsistência (horticultura, pequenas criações de porcos, bois e aves) e agricultura comercial, sendo a yaqona (ing. kava, port., ava ou cavacava) a cultura mais lucrativa. Indianos [fijianos de origem hindu] perfazem quase a metade da população de Fiji, mas em ilhas menores, como Gau, a população é quase que inteiramente fijiana nativa.

${ }^{6}$ A idéia de epistemologia genética proposta por Piaget é aqui modificada pelo reconhecimento de que os humanos são sociais por natureza e de que portanto tudo em nós, de nossos corpos a nossas idéias sobre o mundo habitado, bem como o 
processo no qual essas idéias vão se constituindo no decorrer do tempo, é permeado pelas relações que temos uns com os outros.

7 "Pisinim... denota um intervalo entre o início e o fim de um processo caracterizado essencialmente pela continuação de uma igualdade de determinado tipo. [N. T.: Igualdade, aqui, traduz sameness, talvez mais propriamente traduzível por identidade (no sentido de 'caráter do que permanece igual ou idêntico, do que não muda; qualidade do que é ou permanece o mesmo'), mas o termo poderia ser entendido em outra acepção, mais específica e muito difundida em ciências sociais, estranha aos desígnios do texto.] Essa distintividade do processo define o intervalo. Pisinim, quaisquer que sejam seus conteúdos, não representa simplesmente uma dimensão externa da vida das pessoas - que, assim, as influenciaria ou que seria internalizada - mas está já fundido à pessoa e às suas práticas" (Telban 1998:44). Parte da força da exploração do kay (hábito, jeito, maneira) dos Ambonwari, empreendida por Telban, está na demonstração de que para entender o kay temos de captar a perspectiva temporal aí implicada.

${ }^{8}$ Um de meus informantes - um homem de 31 anos, membro do exército britânico, muito viajado e que viveu fora de Fiji - contou-me recentemente que, quando criança, não conseguia entender como os kalou vu, que ele via como protetores e como uma fonte do bem, também podiam ser responsáveis por mortes por feitiço. Ele tinha 12 anos quando algumas pessoas de sua aldeia, todas aparentadas, foram possuídas por tevoro (os kalou vu, ou Deuses ancestrais, em seu aspecto maléfico), e ele ouviu sua própria avó (FFZ) confessar que desejara vê-lo morto por ter ficado zangada com seu pai [do informante], por não ter feito algo que ela lhe pedira. Ainda não descobri a que conclusão ele — cristão devoto — chegou.

${ }^{9}$ Para uma apresentação convincente da estética do veiqaravi, ver Miyazaki 2000.

${ }^{10}$ Um yavusa é composto de clãs relacionados por descendência ou casamento, que devem obrigações rituais uns aos outros (ver Sayes 1982:87).

${ }^{11}$ Todos os rituais de chefia envolvem um oferecimento inicial da raiz de yaqona como tributo (i sevusevu, uma cerimônia que requer, por assim dizer, o reconhecimento, pelo chefe, da presença de alguém), e a subseqüente redistribuição da yaqona como bebida para todos os presentes. O consumo de yaqona é, ao mesmo tempo, o mais cotidiano e o mais sagrado dos rituais fijianos; um homem é feito chefe supremo graças ao ato de beber o copo oferecido pelo chefe do clã que o instala. A chefia fijiana se constitui, cotidianamente, no esforço para transformar - no ritual (que tem como paradigma as sessões de yaqona) - reciprocidade equilibrada e igualdade entre primos cruzados em tributo e hierarquia entre povo e chefes. Que esse esforço seja, por princípio, interminável decorre do fato de que todos os processos dinâmicos, férteis e afetivos fundamentam-se na relação entre primos cruzados (ver Sahlins 1976:24-46 e Toren 1990:50-118, 1999a:163-181).

${ }^{12} \mathrm{O}$ mesmo se aplica à antítese-fusão de hierarquia e igualdade, que produz a liderança dos chefes (turaga) no vanua e a dos homens casados (turaga) em cada unidade doméstica por via da transformação da troca recíproca equilibrada em tributo (ver Hocart 1913 e Toren 1999a:129-145, 163-181). 
${ }^{13}$ Cf. Turner 1986:209, que fez trabalho de campo em Matailobau, no interior de Viti Levu: "Em Fiji, o mana da cavacava pode ser usado com o fim de estabelecer contato com o mundo espiritual, para o bem ou para o mal. Outro termo para feitiçaria (drau ni kau) é sova yaqona, isto é, 'derramar yaqona'. Os fijianos nunca bebem yaqona solitariamente, nem mesmo na prática da feitiçaria. Nesse caso, bebe-se a dois: um prepara a bebida e o outro pronuncia a maldição enquanto derrama a yaqona. O que os informantes enfatizavam ao descreverem a feitiçaria era a eficácia da própria yaqona".

${ }^{14}$ Em terra (vanua) Sawaieke, termos de parentesco são usados, seja de modo referencial ou como vocativos, para todos os conhecidos de uma pessoa, tanto dentro quanto fora das aldeias e chefaturas, sendo rotineiramente estendidos de modo a assimilar, segundo um princípio classificatório, aqueles anteriormente desconhecidos. A terminologia é dravidiana. Em Toren 1999b, analiso a ontogênese da idéia de que a relação de primo cruzado é a relação crucial para a extensão da compaixão mútua (veilomani) definidora do parentesco, de modo a abraçar todos aqueles de etnia fijiana.

${ }^{15}$ Cf. Hocart 1914; também Firth 1967 [1940]:192, que nota que “[a] maior parte das traduções propostas para mana, por serem de natureza abstrata, não conseguem transmitir a realidade da atitude nativa [...] 'Poder sobrenatural', por exemplo, representa de fato um aspecto do conceito, mas deixa de fora a evidência essencialmente material desse poder, e dirige a atenção para os meios em lugar do produto final".

${ }^{16}$ Tomlinson 2006 argumenta de modo convincente que os missionários produziram a nominalização do mana, transformando-o de verbo em nome [substantivo]. Não posso, entretanto, concordar com ele, quando afirma que "o espectro ameaçador de sua [do mana] perda ou diminuição" é fenômeno recente. Parece-me, antes, provável que os fijianos tenham sempre afirmado que os chefes atuais não podem mana (efetivar) ou não são tão mana (efetivos) quanto os notáveis chefes dos "tempos antigos" (na gauna makawa). O artigo de Tomlinson inclui uma competente discussão da extensa literatura sobre os significados de mana.

${ }^{17} \mathrm{Cf}$. o informante de Hooper, da ilha de Lakeba, o qual, falando do chefe supremo, "sugeriu que mana é uma característica inata que tem a ver com a descendência [...] enquanto que o sau está ligado ao ato de investidura, e que antes da realização desta, o Chefe Supremo o possuía, mas em estado latente...". Ele segue descrevendo o sau como outros descreveram o mana: se as pessoas não fizerem o que o chefe quer, elas sofrerão por causa de seu sau (Hooper 1982:173). Cf. Quain (1948:200), que glosa mana como "poder do chefe" e sau como "poder sobrenatural impessoal"; ver também Hocart 1914.

${ }^{18}$ A fascinante investigação de Martha Kaplan (1995:8) acerca dos modos como a história fijiana é imaginada pelos colonizadores e pelos indígenas de Fiji centrase no homem que veio a ser chamado Navosavakadua. "Ele falava uma única vez, e seu comando era cumprido" (1995:8). Como aponta Tomlinson 2006, "embora o termo mana não fizesse parte de seu nome profético, o conceito está aí subjacente". Para a análise de um exemplo contemporâneo de efetividade da palavra do chefe, ver Toren 2005. 
${ }^{19}$ Não estou sugerindo que os fijianos das aldeias sejam incapazes de testar hipóteses ou que não considerem que isso seja possível mas, apenas, que há casos em que esse teste é inapropriado por não ser capaz de dizer aquilo que se quer saber.

${ }^{20}$ Robbins 2002 contém uma interessante discussão de aspectos do uso da linguagem e do ritual.

${ }^{21}$ É nossa noção da linguagem como instrumento analítico que faz surgirem aquelas inovações tecnológicas que tão poderosamente nos convencem de que somos aqueles cujas idéias são objetivamente verdadeiras, e de que as de outros povos são claramente função de uma suposta subjetividade culturalmente relativa, à qual, em razão de nossa superioridade tecnológica, somos imunes.

${ }^{22} \mathrm{Eu}$ argumentaria que isso vale também para a tão disseminada distinção entre cognição e ideologia, entre o lógico e o simbólico, entre conhecimento prático e conhecimento ritual; ver, por exemplo, Bloch 1985 e 1986.

\section{Referências bibliográficas}

AUSTIN, J. L. 1962. How to do things with words. Oxford: Clarendon Press.

BLOCH, Maurice. 1974. "Symbols, song, dance and features of articulation: is religion an extreme form of traditional authority?" Archives Européenes de Sociologie, 15:55-81.

1985. "From cognition to ideology". In: R. Fardon (org.). Power and knowledge: anthropological and sociological approaches. Edinburgh: Scottish Academic Press. pp.21-48.

. 1986. From blessing to violence. Cambridge: Cambridge University Press.

DAVIDSON, Donald. 1984. Inquiries into truth and interpretation. Oxford: Clarendon Press.

FIRTH, Raymond. 1967 [1940]. "The analysis of mana: an empirical approach". In: Tikopia ritual and belief. London: George Allen and Unwin. pp. 174-194.
HOCART, Arthur Maurice. 1913. “On the meaning of the fijian word turanga [sic]". Man, 13:140-143.

1914. "Mana". Man, 14:97-101.

1952. The northern states of Fiji.

Occasional Publication, 11. London: Royal Anthropological Institute.

HOOPER, Stephen Phelps. 1982. A study of valuables in the chiefdom of Lau, Fiji. Ph. D. Thesis, University of Cambridge.

KAPLAN, Martha. 1995. Neither cargo nor cult. Ritual politics and the colonial imagination in Fiji. Durham: Duke University Press.

MILNER, George. 1972. Fijian grammar. Suva: Government Press.

MIYAZAKI, Hiro. 2000. "Faith and its fullfillment: agency, exchange and the fijian aesthetics of competition". American Ethnologist, $27(1): 31-51$.

QUAIN, Buell. 1948. Fijian village. Chicago: University of Chicago Press. 
ROBBINS, Joel. 2001. "Ritual communication and linguistic ideology: a reading and partial reformulation of Rappaport's theory of ritual". Current Anthropology, 42:591-614.

SAHLINS, Marshall. 1976. Culture and practical reason. Chicago: Chicago University Press.

SAYES, Shelley Ann. 1982. Cakaudrove: ideology and reality in a Fijian confederation. Ph. D. Thesis, Australia National University.

TELBAN, Borut. 1998. Dancing through time. A sepik cosmology. Oxford: Clarendon Press.

TOMLINSON, Matt. 2006. "Retheorizing mana: Bible translation and discourse of loss in Fiji". Oceania, 76(2):173-186

TOREN, Christina. 1990. Making sense of hierarchy. Cognition as social process in Fiji. London School of Economics, Monographs in Social Anthropology, 61. London: The Athlone Press.

1999a. Mind, materiality and history. Explorations in fijian ethnography. London: Routledge.

1999b. "Compassion for one another: constituting kinship as intentionality in Fiji". Journal of the Royal Anthropological Institute, 5:265-280.

2002. "Anthropology as the whole science of what it is to be human". In: R. Fox e B. King (orgs.). Anthropology beyond culture. London: Berg. pp. 105-124.

2005. "Laughter and truth in Fiji: what we may learn from a joke". Oceania, 75(3):268-283.

2006. "The effectiveness of ritual". In: F. Cannell (org.). The anthropology of christianity. Durham: Duke University Press. pp. 185-210.

TURNER, James W. 1986. "The water of life: kava ritual and the logic of sacrifice". Ethnology, 25:203-214. 


\section{Apêndice}

\section{Texto 1}

E dua tiko na Kalou ia da sega ni raica. Ia, e rawa ni da vakadinadinataka tiko ni da vakadinadinataka ni dua na Kalou. [...] Au vakadinadinataka ni dua na Kalou. E levu na ka au na vakaraitaka yani oqo vei iko - e dua na liwa ni cagi. Eda taroga: e lako maivei na cagi? Dua, na matani siga, o cei bulia na matanisiga. Na vula, o cei bulia na vula? Na kalokalo, o cei bulia na kalokalo? Na vunikau oqo, o cei e bulia? Na manumanu, o cei e bulia? Na co, o cei e bulia? Na tau ni uca, na... tubu ni... nodra tubu na vunikau, era tubu vakacava? [...] Na ika lelevu mai wai. ... da kila... E so, e so na tamata vuku ena gauna oqo era tukuna ni sega na Kalou. Ia me ra tukuna ni sega na Kalou, e tubu vakacava na vuanikau? O cei e bulia na vunikau? O cei e bulia na matanisiga? O cei e cakava na ua? O cei e cakava na di ni mati? [...] O cei e bulia na ika lelevu? [...] Keimami sa kila ga ni dua tiko na Kalou o koya e bulia kece na ka kece tu oqo.

\section{Texto 2}

Kalou vu sa tiko tiko ga. [...] kalou ga ni vuravura - na kalou vu. Na kalou vu... oqo e tautauvata, o ira oqo me tamata ga. O ira noda vu makawa mai na gauna ya, koya vata ko ira me kalou mai na gauna sara ya.[...] O ira na kalou vu, o ira ga na... tukada vakavica sara. [...] E na gauna ni ko qaravi koya kina na qai basika mai o koya ... [...] Mevaka nomu qarava na Kalou. Ni ko vinakata mo qarava na Kalou, na Kalou sa na qai solia vei iko na ka o vinakata. Tautauvata na kalou vu, ke ko qarava. Ke ko qarava na kalou vu e na solia mai na kalou vu na ka o vinakata. Ia, ka ga ni vuravura oqo. Sa mana tiko. [...] Ke ko qarava. Sa mana. Io, kau sa tukuna oti, ka ga ni vuravura oqo. Kalou... kalou levu... kalou dina... sa veicalati. Na kalou levu o koya e lewai ira. [...] O koya kaukauwa cake sara mai vei ira kece. Ia, o koya, tukuna e na i vola tabu, sa... sa sega tale ni dua na kalou e lomalagi e vuravura me tautautvata kei koya. [...] Me tukuna va oqo e na ivola tabu ni Kalou levu, koya Kalou dau vuvu. [...] Sega ni vinakata tale o koya mo qarava tale e dua tale na kalou e vuravura oqo. [...] E vinakata ga o koya mo qaravi koya ga. Io. Ke ko qaravi tiko e dua na kalou vu kena ibalebale sa veicalati vata kei na nona lewa. Kevaka... au tukuna gona vei iko, se vei kedaru, na kalou vu na nodra kaukauwa yaco ga na vuravura oqo.

\section{Texto 3}

Da kila vakacava? Ni o raica na kena irairai, na kena ituvaki na nona bula vata ga kei na nona matavuvale. [...] Ni ko via kila vakavinaka ni ko raica na nona matavuvale kei iratou na gone, o ratou na vuli o ratou sega ni yacova na vuli vinaka. Levu na ka dredre eratou na sotava, levu na ka dredre eratou na sotava eratou na luvena. Raica 
tale ga nodratou bula ni vuvale e sega ni vinaka. [...] E so, ni dau ra beitaka ni qaravi tevoro, kalou vu, e so kau sa kaya oti ya e vakaraitaka vei ira na luvena, na luvena e sega ni vakawati, ke ira vakawati era sega ni vakaluveni. Kevaka era vakaluveni, e na dua ga na luvedra. Ia, e so... Ian aside here, a brief conversation with a child who comes with a message] e so e dau qarava tiko na kalou vu, dau qarava tiko, oti ya era sa kila ni kena sa ca - au dau rogoca ga - era dau vakasuka tale, e ra dau vakasuka.

\section{Texto 4}

E so - kena i talanoa eda rogoca - e so ra qarava ga na nodra e loma ni vale. E so era veikilai, era veikilaitaki vakaveiwatini — kila na turaga, kila na marama. [...] Ni dua sa tukuna va oqo, <koya vakatevoro>, qai tukuna talega e so, <ia oqori sega ni kila duadua>. [...] Kila talega na watina.

\section{Texto 5}

... na nona gunu yaqona sa sega ni vaka na gunu yaqona na tamata, sa lako tu e veisiga: gunu yaqona, gunu yaqona. Koya vata kei... koya vata kei na watina erau sa gunu yaqona tiko e nodrau vale erau ruarua. Ke da... ni da gunu yaqona eda veitalanoa, lelevu.

\section{Texto 6}

Kau sa kaya oti ya, io... e vaka i cavacava ga na i vakaiyalayala ga, vakaiyalayala ga... E dua na gauna sa na qai vuki tale mai na kalou vu me kemu meca, qai kati iko tale. Va ya. Sega ni rawa ni qarava tiko me tawa mudu me sa lako tu ga, lako tu ga, lako tu ga. E na yaco na gauna ni drau veimecaki tale. [...] Kemu meca tale na kalou vu. [..] Ko i au sa tukuna oti e na gauna ya na nomu veiyalati, na nomu veiyalati vataki koya me donu tu ga e na veigauna. Me donu me donu. Mai na gauna ni ko sega ni cakava tiko na nomu veiyalati, gauna sara ga e na kati iko tale kina o koya.

\section{Texto 7}

Chris. Ia ko vakabauta na talanoa me baleti rau?

Mika. O iau, levu na i talanoa va oqori au dau rogoca au sega ni dau vakadinadinataka baleta eda sega ni raica e dua na ka me da raici koya me da raica sara e matada qai da beitaka. E so beka raica, e so beka raica era sa beitaki rau kina, ko i au mada ga... au sega ni vakadinadinataka baleta au sega ni raica e mataqu e dua na ka erau cakava. Ia o ira beka, o ira beka na tu makawa ena koro oqo, kedaru na lako mai, kedaru na lako vou mai, kedaru sega ni raica e dua na ka, kedaru sega ni tukuna rawa e dina se lasu. [...] E so, e so na vakamacala ni ka oqo ni ko ira ka qarava tiko na kalou vu na kena i vakamacala kau sa dau rogoca vei ira ni ra oqo na tamata dau loloma, era dau tamata dau veikauwaitaki. Me ra ubia tiko kina na nodra itovo me da kakua ni 
kila tiko ni ra qarava tiko na kalou vu e ra dau kauwaitaki keda.

Chris. Ia kena ibalebale sa dredre sara...

Mika. Dredre. Vakavo ke iko raici koya ni qarava tiko ke ko sa raica sara e matamu ni gunuva tiko e dua na i talo ni yaqona, vosavosa tiko.

Chris. Ko sa raica?

Mika. Sega au kaya mada.

Chris. Ah.

Mika. O sa qai rawa ni kila ni o koya. E ra tukuna o ira na dau tukuna ni na tamata ni da sa raica ni da sa beitaki koya ni qarava tiko na kalou vu e so na nona i tovo 'ya — dau veikauwaitaki, dau loloma, baleta me ubia tiko kina o koya na nodra... dau lailotu, e so... era beitaka, e so era dau beitaki, era dau vunau baleta me ra ubia tiko kina na nodra itovo.

[...] Chris. Kena i balebale ni sa sega ni rawa...

Mika. ... mo kila.

Chris. Ia, sega ni rawa

Mika. Vakavo ke sa raica, mo sa raici koya e na dua na vanua. [...] E so, e so dau tukuna - au sa bera ni raica mada - e so era dau tukuna ni ra dau meketa na vula. Na vula? E dau meke tiko, va oqo, [moving his hands in a fast meke] va oqo. E so era tukuna. Aya nodra i vakarau. Io. E so era dau toboka, era sa dau toboka na tamata ko ira meke vula tiko.

Chris. Sa dina?

Mika. Io. E so era tukuna.

Chris. E na koro, e loma ni koro?

Mika. E loma ni koro kei na veikoro tale e so e Viti. Ena ka oqo, Christina, e tu kece ga na koro kece vakaViti e tu e so na tamata era dau beitaki tu ni ra dau vakadraunikau. Veikoro kece e Viti.

Chris. Sa dina... eke talega, e Sawaieke?

Mika. Eke talega e tu e so.

Chris. Ia na ka dredre vei au...

Mika. Io.

Chris. ... ...ko kila... vakacava?

Mika. ... ...ko kila... vakacava?

\section{Texto 8}

Chris. Ia, ko vakabauta Peni, ko sa tukuna vei au ni sa tiko eke, e Sawaieke, e so. Ko kila vakacava ni sa tiko eso?

Mika. Na i talanoa ga da rogoca. Na veitalanoa ga va oqo, va oqo, da rogoca.

Chris. Ia, raica - oqo... na talanoa oqo, ko kila vinaka ni sa levu na - na cava na vosa? - na kakase. 
Mika. Io. Na kakase. Io. Dina oqori. Dina oqori. Kakase

Chris. Levu.

Mika. Kakase. Koya eda rogoca, koya na i talanoa me va oqo, talanoa me va oqo. E so era talanoa era via vakacacani, e? Spoil? Spoil each other? [...] E sega ni raica rawa e dua kena i vakadinadina.

\section{Texto 9}

Chris. Ia Italatala Vosaki sa tukuna vei au ni sa dau tukuna vua < kua ni rere > $<$ Taura na ika, vakavinavinaka, vakasaqa. E na kana vinaka. > Sa sega ni vakabauta o koya na italanoa vaka oqo.

Mika. Mmm. Ya na ... ya na vakabauta vaka Viti.

Makereta. [wakes up, breaks in] E sega ni rawa ni yali na ka ya vei keimami na kai Viti.

$[\ldots]$

Mika. O koya e sega ni rawa ni beitaka e dua na tamata. I talatala. O koya na ka kece sa kau mai, o koya na ciqoma. Sega ni rawa vakadua ni beitaka na tamata sega ni tukuna o koya <ka oqori, ka oqori, ka oqori>. Sega. O koya e na taura ga, e na vakavinavinaka. Oyo na nodra itovo kece na i talatala. Nodra itovo kece ga na italatala ni lotu, na ivakatawa, nodra i tovo kece ya. Era sega ni rawa ni vakaduiduitaka na tamata, ka kece e solia mai eke solia mai eke, era ciqoma. [...] Ciqoma. Ciqoma. Ciqoma ka vakavinavinaka. [...] Na vakabauta vaka ivola tabu, vaka lotu Karisito: kakua ni beitaka e dua na wekamu. Taura kece ga na ka e sa solia mai vei iko na wekamu.

\section{Texto 10}

Makereta. [...] na ka ya era bula ga mai kina na neimami qase. Ra bula ga mai me ra vakalou kina kalou vu. [...] E sega ni rogoca o ira tale eso vei keimami na lotu e na tiko ga e so na tamata era vakabauta tiko na kalou tani, kalou vu. Era na qarava, veitalia kevaka e curu tiko na vale ni lotu era qarava ga baleta oya a nodra kalou ga na neimami qase.

\section{Texto 11}

Au tara saka tu mada ga na wa ni tabua, ni bula vinaka na turaga e nodatou vanua, sautu tiko noda vanua me vanua veilomani, a rogoci tu mada ga na vosa. Mana e $i$ dina [cobo]. 
Resumo

A análise de uma conversa particular que se deu em Fiji sugere que sabemos o que é verdade basicamente por aquilo que se evidencia aos nossos olhos e aos de outras pessoas. Mesmo assim, nesse caso fijiano, a verdade não é necessariamente a priori, não é sempre dada na natureza das coisas. Em certos casos - a feitiçaria, por exemplo - o que é verdade permanece por ser descoberto. Isso também se aplica à questão de saber se as palavras e os atos de uma pesoa são ou não mana, isto é, materialmente eficazes. A idéia fijiana é que o discurso, ou mais genericamente a palavra (vosa), quando falada ou escrita, pode ser mana, eficaz, e assim aquilo que é verdade (dina) pode ser um resultado, e não algo já dado. Segundo o argumento aqui desenvolvido, por ser o mundo circundante capaz de garantir todos os significados que os seres humanos podem produzir, nossos diversos entendimentos (como antropólogos e como pessoas) são tão passíveis de análise histórica quanto os de outrem. Segue-se que o poder explanatório de nossas etnografias deve residir na operação de tornar analíticas as categorias dos informantes. Finalmente, o artigo usa material fijiano para afirmar que as idéias acerca daquilo para que serve a linguagem (sua força moral) são cruciais para se entender o que é dito, e indica a utilidade analítica do desnudamento, em cada caso específico, da ontogênese da força moral da linguagem.

Palavras-chave: Ontogênese, Conhecimento, Verdade, Mana, Feitiçaria.

\section{Abstract}

Analysis of a particular conversation held in Fiji suggests that we know what is true primarily by the evidence of our own and others' eyes. Even so, in this Fijian case, truth is not necessarily a priori, it is not always given in the nature of things; in certain cases - witchcraft, for example - what is true remains to be found out. Ditto for whether or not a person's words or acts are mana, that is to say, materially effective. The Fijian idea is that speech or, more generally the word (vosa) as it is spoken or written, may be mana, effective, and thus what is true (dina) may be an outcome rather than already given. The objective of the paper is not to translate Fijian terms, but to render them analytical. The argument here is that because the environing world provides for all the meanings that humans can make, our own understandings (as anthropologists and human beings) are just as amenable to historical analysis as the next person's; it follows that the explanatory power of our ethnographies must be made to reside in rendering our informants' categories analytical. Finally, the paper makes use of the Fijian material to argue that ideas about what language is good for (its moral force) are crucial to understanding what is said and suggests the analytical utility of laying bare the ontogeny of the moral force of language in any given case.

Key words: Ontogeny, Knowing, Truth, Mana, Witchcraft. 